\title{
VIEWPOINT
}

\section{Research on the human components of global change}

\author{
Next steps
}

\section{Roberta Balstad Miller and Harold K. Jacobson}

\begin{abstract}
Although research on human interactions in global change is advancing rapidly, future research in this field will require changes in the scale and scope of social science research projects. The social sciences will also require new institutional structures that can organize and manage largescale, multinational, and multidisciplinary research. This article (a) summarizes what has taken place in planning for research on the human components of global environmental change; (b) assesses the readiness of the social science community to undertake large-scale research in this field; (c) identifies areas where largescale research can and should be undertaken; and (d) suggests criteria that should guide the social science community as it moves towards largescale research projects.
\end{abstract}

Roberta Balstad Miller was with St Anthony's College, Oxford, when this article was written. She is now with the Division of Social and Economic Science, National Science Foundation, Washington, DC 205550, USA. Harold Jacobson is with the Center for Political Studies, Institute for Social Research, University of Michigan, PO Box 1248, Ann Arbor, Ml 48106-1248, USA.
After several years of planning and preparation, research on human interactions in global environmental change is advancing rapidly both within countries and internationally. There is a growing convergence on the importance of understanding anthropogenic causes of global change and on the kinds of social science research that must be done to provide this understanding. These are important accomplishments. But in some significant ways, planning for global change research in the social sciences may have outstripped the research that is taking place and fallen short of what needs to be done.

Too often, global change research in the social sciences is still practised as a cottage industry. It is conducted by a limited number of researchers with limited disciplinary perspectives and is focused on narrowly defined problems conceived on a national or local scale. This nationally delimited, single-discipline research is the type of work social scientists have been conducting for several decades and do very well. It fits the nature of social science as it has been traditionally perceived and contributes to our understanding of global change.
However, global environmental change also presents social scientists with research problems of a new scale and scope that can be addressed only with big science concepts, techniques, and goals. For social science research to continue to advance, social scientists must have the capacity to do interdisciplinary global-scale research at the same level of quality and meeting the same scientific standards as are now characteristic of nationally or locally focused research.

The problem of scale and scope is not confined to research on global change, but will increasingly be encountered throughout the social sciences. The traditional mode of organization for social science research is incapable of dealing with this type of research need. To understand global change, for example, social scientists must expand the spatial, temporal, and disciplinary scope of their research. This will require not only a multinational focus and multidisciplinary analysis, but also both multinational and multidisciplinary participation in the research effort.

To accomplish this, the social sciences will require new institutional structures which can organize and manage 
An earlier version of this article was presented at the 1992 Annual Meeting of the American Association for the Advancement of Science, Chicago, IL, 6-11 February 1992. The authors would like to thank Dr Richard C. Rockwell, Executive Director of the Inter-University Consortium for Political and Social Research, for his comments on an earlier draft of this paper.

${ }^{1}$ The ISSC is comprised of fourteen international social science associations - the International Association of Legal Science; the International Economic Association; the International Geographical Union; the International Law Association; the International Institute of Administrative Science; the International Peace Research Association; the International Political Science Association; the International Sociological Association; the International Studies Association; the International Union of Anthropological and Ethnological Sciences; the International Union of Psychological Science; the International Union for the Scientific Study of Population; the World Association for Public Opinion Research; and the World Federation for Mental Health - and the International Federation of Social Science Organizations.

${ }^{2}$ For the reports of the meetings, see David Braybrooke and G. Paquet, 'Human dimensions of global change: The challenge to the humanities and social sciences', Transactions of the Royal Society of Canada, Vol V, No II, 1987, pp 271-291; International Federation of Institutes for Advanced Study, The Human Response to Global Change: Prospectus for an International Program, International Federation of Institutes for Advanced Study, Toronto, 1987; Jostein Mykletun, One Earth-One World: Report from a Research Policy Conference on Environment and Development, Nonwegian Research Council for Science and the Humanities, Oslo, 1988 Uno Sveden and Bo Heurling, eds, Swedish Perspectives on Human Response to Global Change, Swedish Council for Planning and Coordination of Research, Stockholm, 1988; and Harold K. Jacobson and Cheryl Shanks, Report of the Ann Arbor Workshop on an International Research Program on Global Change, Institute for Social Research, Ann Arbor, MI, 1987. ${ }^{3}$ Tang Xiaoyan and Harold K. Jacobson, Human Dimensions of Global Environmental Change: Proposals for Research, Institute for Social Research, Ann Arbor, MI, 1988.

${ }^{4}$ The Human Dimensions of Global Change: An International Programme on Human Interactions with the Earth, International Federation of Institutes for Advanced Study, Toronto, 1989.

${ }^{5}$ See National Research Council, Commission on Geosciences, Environment, and Resources, Committee on Global Change, Toward Understanding Global Change: Initial Priorities for the International Geosphere-Biosphere Programme, Natcontinued on page 172 such diverse components of largescale research problems as data collection, calibration and analysis, and the training of new researchers. These structures must also be capable of integrating these activities of researchers from a variety of countries and disciplines. Without adequate institutional support, global-scale comparative resarch will not be possible equally important, research in this field will not accomplish what both social and natural scientists hope it will accomplish, nor will it meet the expectations that governments and policy makers now have for the field.

Our purposes in this article are:

- to summarize what has taken place in planning for research on the human components of global environmental change;

- to assess the readiness of the social science community to undertake large-scale research in this field;

- to identify areas where large-scale research can and should be undertaken;

to suggest criteria that should guide the social science community as it moves toward large-scale research projects.

\section{The initial planning effort}

Planning for social science research on the human dimensions of global environmental change began in 1986 , significantly later than the planning for global change research in the natural sciences. The International Council of Scientific Unions (ICSU) and the World Meteorological Organization (WMO) launched the World Climate Research Program (WCRP) in 1979, and after several years of preparation ICSU adopted the initial framework document for the International Geosphere-Biosphere Programme (IGBP) in September 1986. After this, the IGBP undertook an additional planning period of four years, so that the programme did not actually start until 1990.

Social science planning for research on global change grew out of several different initiatives. As a result of discussions in its General Assembly, the International Social Science Council (ISSC) created an ad hoc planning committee in December 1986 to explore the possibility of establishing a social science programme on global environmental change.' During the following year, independently organized meetings to explore the possibility of a social science research agenda on this topic were held in Canada, Norway, Sweden, and the USA. ${ }^{2}$ Further meetings, involving more extensive multinational participation, were held in 1988. Social scientists and environmental scientists from China and the USA met in Beijing in May, ${ }^{3}$ and in September the International Federation of Institutes for Advanced Study, the International Social Science Council, the United Nations University, and other organizations sponsored a broad international meeting of social scientists in Tokyo. ${ }^{4}$ As a result of these various meetings, social scientists became increasingly aware of the contribution that their research could make to the development of an understanding of global environmental change.

In the meantime, there was a growing rccognition among participants in the various global change research activities in the natural sciences that global change research could not be confined to the natural phenomena, but had to encompass anthropogenic forces as well. Within the USA, the Committee on Global Change, under the chairmanship of Professor Harold Mooney, identified Human Interactions as one of four major areas for global change research in its 1988 report. ${ }^{5}$ Moreover, the US Global Change Research Plan and budget for FY 1990 contained for the first time a component on human interactions. ${ }^{6}$ In the National Science Foundation, a research programme was established in late 1988 in the Human Dimensions of Global Environmental Change. Similar developments were occurring in other countries. As early as 1989 , the IGBP began to discuss collaboration among social and natural scientists, and in 1990 the Second World Climate Conference adopted a resolution calling for increased research interactions between climate researchers and social scientists. 


\section{Consensus on topics and structures}

Planning for international social science research came to an initial conclusion in November 1990 when ISSC's General Assembly adoped $A$ Framework for Research on the $\mathrm{Hu}$ man Dimensions of Global Environmental Change, and launched the Human Dimensions of Global Change Programme (HDP). The General Assembly's decision followed the first Scientific Symposium on the Human Dimensions of Global Environmental Change. This symposium considered how the social and natural sciences would have to work together to understand the processes of global change, examined and vetted the Framework, and explored two research issues in depth - data requirements and the broad topic of land use and land cover change. ${ }^{8}$ Biannual scientific symposia will be a continuing part of the Human Dimensions Programme.

Seven topics were identified in the Framework to organize social science research. Although other reports use somewhat different terminology, the substance of the topics identified in the reports produced at the various international and national meetings is quite similar. The topics for social science research adopted by the ISSC General Assembly include the following:

(1) Social Dimensions of Resource Use.

(2) Perception and Assessment of Global Environmental Conditions and Change.

(3) Impacts of Local, National, and International Social, Economic, and Political Structures and Institutions.

(4) Land Use.

(5) Energy Production and Consumption.

(6) Industrial Growth.

(7) Environmental Security and Sustainable Development.

The fourth, fifth and sixth topics cover what have been clearly identified as the proximate anthropogenic causes of global environmental change: changes in land use and land cover; energy production and consumption; and industrial growth broadly defined.
Sometimes the last two topics are conflated under the heading of 'industrial metabolism'. 9 The first three topics highlighted in the Framework deal with issues somewhat less directly related to global environmental change but more basic. Population, economic growth, and technology (topics included within the social dimensions of resource use) are the fundamental anthropogenic driving forces in global change. 'These are modified by the way individuals - that is, members of the general public, business and labour leaders, governmental officials - perceive and value global environmental conditions and then behave. Their behaviour is shaped by the social, economic, and political structures within which they exist.

National research planning activities have been moving in tandem with the international activities. In the USA, the end of the initial planning stage was marked by the publication of Global Environmental Change: Understanding the Human Dimensions in January 1992. ${ }^{10}$ This report was prepared by the Committee on the Human Dimensions of Global Change of the Commission on the Behavioral and Social Sciences and Education of the National Research Council at the request of the National Science Foundation. It made recommendations on data, research topics, research funding, and training. Comparable documents have been published for other countries. ${ }^{11}$

Under the auspices of the International Group of Funding Agencies for Global Change Research (IGFA), national research funding organizations now meet regularly to discuss priorities and funding policies in this area. From the first meeting of this group in Bonn in 1990, the social sciences were included with the natural sciences. In addition, representatives of multinational funding programmes such as those of the European Communities and international research programmes such as IGBP, WCRP, and the international Human Dimensions Program attend the IGFA meetings.

Research planning is, of course, not over. Planning for research, including adapting current plans to changing 
research needs, must go on continuously as the research field becomes more sophisticated and complex. However, enough research planning has taken place to identify the broad areas where research needs to begin. As a result of the various activities that have taken place since the end of 1986 , there is an overall consensus on the general outlines of the topics that need to be covered and an international organizational structure in place to coordinate it. What remains to be accomplished is detailed preparation for the next stage. This will involve creating the infrastructure and resources that will permit social scientists to conduct research of the scale and of the scope required for understanding global change. These activities will of necessity be big science projects. Organizing them is made difficult by the fact that the need for such projects has hardly been grasped.

\section{Readiness and preparatory work}

Before the social science community can undertake large-scale research on the human dimensions of global environmental change, certain fundamental questions should be raised about whether it has the capacity to do research on this scale. Discussing these issues more than two decades ago, Alvin M. Weinberg said that the rationale for undertaking big science should be based on both internal and external criteria. ${ }^{12}$ Internal criteria should relate to the quality of the science likely to result and should encompass such topics as whether the field is ready for exploitation and whether scientists are available with the training necessary to do the research. External criteria address why a particular project should be done. The external criteria are most important in obtaining public support for largescale science and are discussed in the conclusion of this article. Weinberg's advice remains valid today. A scientific community entering a new field like global environmental change must have relevant theory, data, and people if it is to produce good science Equally important, to maintain a new focus over the time required for cumulative research findings, the community must have the institutional infrastructure to support the necessary research activities and research resources.

In assessing the readiness of the social sciences to enter this field, the first issue to consider is the theoretical base for research on global change. Experience clearly indicates that research will not be successful unless there is an adequate theoretical foundation for the work that is to be done. There are several concepts and theories that provide a strong foundation for research on the major topics included in the consensus research agenda. For instance, population is a driving force in bringing about global environmental change, and the second half of the twentieth century has been marked by especially rapid population growth. It is known though that as countries pass from a pre-industrialized to an industrialized stage they go through a transition in which first mortality and then natality rates drop. The demographic transition theory explains this and indicates factors that affect the pace and extent of the transition. Beyond the theory of the demographic transition those theories that are most relevant include theories linking energy use and other resource use with levels of economic development and with prices; theories about the pace and direction of technological innovation; theories about attitude formation and change; and theories about the operation and responsiveness of economic, political and social systems.

A next step is to explore linkages among the concepts and theories. The Social Process Diagram shown in Figurc 1 will contribute to understanding and visualizing these linkages by making the connections and interactions among multiple types of human activities explicit. This Social Process Diagram was produced by the Human Interactions Working Group sponsored by the Consortium for International Earth Science Information Network (CIESIN) and the Aspen Global Change Institute in a 1991 summer meeting.

Global change research in the biological, chemical, and physical sciences was advanced significantly by the ela-
Alvin M. Weinberg, Reflections on Science, MIT Press, Cambridge, MA 1967, p 65 . 


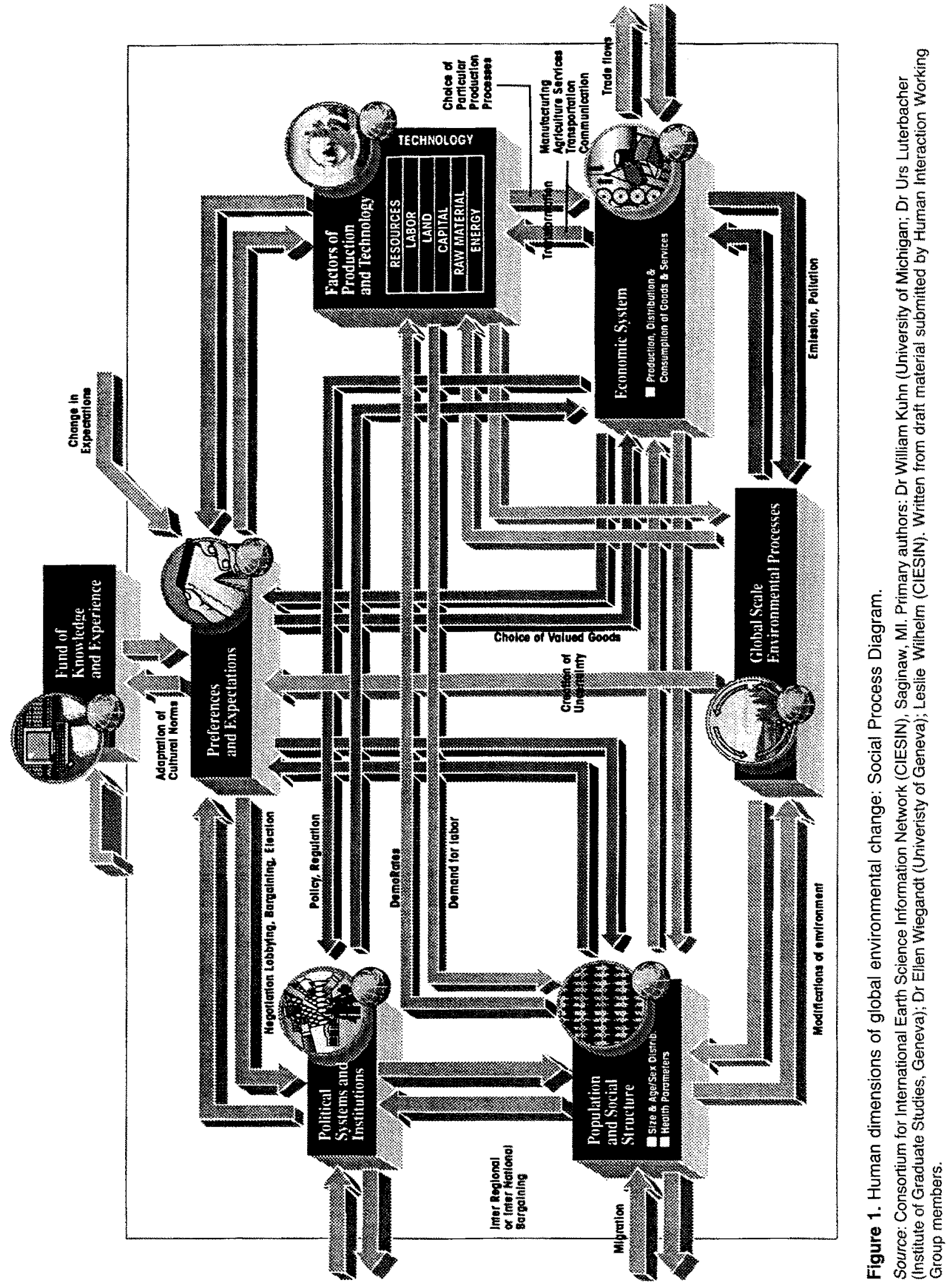


boration and widespread acceptance of a wiring diagram that was developed in 1986 by Francis P. Bretherton and others. At that time Professor Bretherton chaired the Earth System Sciences Committee of NASA's Advisory Council. The Bretherton diagram depicted the linkages among the biological, chemical, and physical processes that are critical to understanding global change. Human interactions were included in the Bretherton diagram, but only as a 'black box'. Human interactions research had long needed the equivalent of a Bretherton diagram to convey visually the interconnections among diverse cultural, economic, political, social, and instilutional phenomena and to begin to relate these theoretically. Regardless of whether or not the Social Process Diagram will be the one that will ultimately organize research on the human dimensions of global environmental change, it can serve as a point of departure because it encompasses the several topics that the research planning consensus has identified as the key socioeconomic factors in this field.

Since social scientists dealing with global change will come from a variety of disciplines, and since research on the human dimensions of global change must be multidisciplinary, knowledge of these concepts and theories, and the literature in which they arc cmbedded, must be diffused more broadly among the social science community. James A. Edmonds is leading an international effort to bring together information on both continuing and completed social science research on global change to help fill this gap. ${ }^{13}$

The social science community also needs to have a clear sense of what data are available for work in this area. With the support of CIESIN, IIDP creatcd threc working groups to conduct preliminary inventories of extant data: one on survey research data; a second on demographic data; and a third on economic data. Two of the groups have completed the initial stage of their work. The reports of the groups on survey research and on demographic data have been published. ${ }^{14}$
It is clear from the assessment of survey research data that such data are most frequently available for national rather than multinational research. A major problem social scientists face in studying global change is the lack of data for cross-national comparisons and global analysis. The social sciences have developed the methodological tools over the past two decades to analyse multicountry data and make multinational comparisons, but for research on perceptions and assessments of global change, they lack appropriate data. Although the survey research data working group pointed out the necessity of extending the inventory that they inaugurated, most of their recommendations involved the collection of additional data.

There are ample demographic data that, thanks to the statistical programmes of international governmental organizations, have been collected according to internationally comparable standards. But these data are also inadequate for the type of work required for the analysis of global environmental change. A major problem is that the demographic data are not adequately geo-referenced.

Another issue in assessing the readiness of a scientific community for research is the availability of qualified personnel. Within most of the social science disciplines, there has been a core of scholars who have specialized in research on environmental issues at the intersection of various disciplines. Because of the increasing salience of the topic of global change, they have been joined by others, but there still is more research to be done than trained people to do it. The field, if it is to meet its potential, needs to attract additional social scientists.

Steps have been taken to support graduate training for additional social scientists to work on global environmental problems. Within the USA, the Department of Energy and the National Aeronautic and Space Agency have inaugurated large fellowship programmes for graduate students. The UK has also started a fellowship programme. On the international level, the Rockefeller Foundation has inaugurated a major programme to assist scholars and officials in the pri- 
vate and public sectors in developing countries become proficient in global environmental change studies. But formal fellowship programmes are not the only way to train researchers. Social scientists, particularly senior researchers but also graduate students, will receive valuable on-the-job training through participation in large-scale research programmes. For example, IGBP has launched what it calls the Global Change System for Analysis, Research and Training (START) initiative, which will create a number of regional global change research centres. ${ }^{15}$ Research training will be conducted in these centres as part of their continuing research activities. Because social science is included within the START mandate, HDP has been cooperating with IGBP in working towards the development of the START system. However, although research training through participation in large research projects is perhaps the best way to train large numbers of social scientists from a variety of countries, there are as yet no other big science projects in which this type of training can take place.

In terms of basic concepts, theory, and initial data assessments, the social sciences are ready to embark on largescale research on the human dimensions of global environmental change. In terms of providing training for needed researchers and obtaining global scale data resources, the social sciences require such projects. What, then, are the next steps?

\section{Next steps}

Before addressing the types of activities that should be launched, it is useful to return to the issue of how the scale and scope of social science research on environmental change is different from most traditional social science research and what are the implications of this for new types of research activities. Because research on global change encompasses both local and global phenomena, the scale of research on global environmental change can be either at the local or the global level. Although it is true that specific human actions that contribute to global change are conducted at a local level and that adaptation to environmental change has traditionally occurred at that level, these actions, repeated over time, can have large cumulative effects at a global scale. For this reason, research on the human dimensions of global environmental change must have the capacity to illuminate phenomena at both levels and to identify the processes by which actions at one level are transmuted into the other. Another reason why social scientists must be able to move between the local and global levels of research is that the growing economic and social interdependence of countries requires a consideration of local activities in their global political and economic contexts.

Research conducted with this broad and variable focus cannot he confined to the industrialized countries: for substantive reasons, it must encompass the developing countries as well. First, the developing countries are increasingly becoming the most significant producers of greenhouse gases. For example, after the USA, the largest current emitters of greenhouse gases are the countries formerly in the Soviet Union, Brazil, China, and India. ${ }^{16}$ Moreover, given their projected population and economic growth, the developing countries will soon become the most significant sources of greenhouse gas emissions. Second, because the agricultural sectors of these countries contributc large and in some cases predominant shares to their gross national products and provide employment for substantial proportions of their populations, and because their economies have little flexibility, the developing countries are more vulnerable than the industrialized countries to the consequences of global change. ${ }^{17}$

Changes in scope and scale are also needed if the disciplinary mix of social science research on global environmental change is to be improved. Global change research must be multidisciplinary because the disciplines in social sciences, as they have previously been organized, examine discrete segments of human social behaviour. But the human behaviour resulting in the anthropogenic causes of global change cuts across the traditional seg- 
mentation of the disciplines. The mix of problems in global change, which could involve study of the size and growth of populations, their physical, economic, and behavioural characteristics, and their institutional structures and the density of their organizational activity, is too broad for any functionally defined discipline.

Demographic and economic change must be studied in combination, not singly. Similarly, legal and administrative regulations concerning specific aspects of global change, such as land use/land cover, cannot be fully effective if they run counter to economic forces. ${ }^{18}$ The same point could be made with respect to cultural, social, and psychological forces and the impact of tradition on collective and individual action. Policies need to be studied holistically, not by single disciplines. That global change research should be multidisciplinary has been widely accepted in principle, but as yet there has not been enough thought given to the practical implications of multidisciplinary research.

The individual and team efforts that have been started in various global change research programmes include some that are multidisciplinary, but none that are truly global. There is, however, one prominent example of a social science research project that had a global orientation - the World Fertility Survey (WFS). The WFS is an extremely useful model for the type of work that needs to be done in the field of global change. An important theory - the theory of demographic transition - provided a framework for the survey. The survey involved a large-scale data collection on a country-by-country basis, a task that could be accomplished only on a collaborative international basis. Fortyone developing countries and 21 industrialized countries were involved. Although the WFS was funded by the US Agency for International Development and the United Nations Fund for Population Activities, it was planned and implemented by an international scientific committee. Planning for the WFS began in the 1960s, an international office was created in 1972, and the survey was implemented between 1974 and 1984. Although the data were collected through surveys in each country, they were collected according to a common framework and in principle became common property. They have been used extensively for research and for the development of national and international public policy. The benefits for participating countries included data on the important issue of reproductive behaviour and training for the social scientists who took part in the survey.

Perhaps because the WFS was largely confined to one discipline and because it was administered as a onetime survey rather than as part of an ongoing monitoring process, few social scientists outside of demography know about its results and the modalities through which it was conducted. Fortunately, there is a good history of the WFS. ${ }^{19}$ As social scientists think about big science research on the human dimensions of global environmental change, the experience of the WFS should be consulted frequently, and the progress of the follow-on to it, the Demographic and Health Survey (DHS), which is currently being conducted, should be monitored carefully.

There are other examples of largescale multinational social science research activities that can serve as models for big science in the field of global change. The Luxembourg Income Survey (LIS) provides fully comparable microdata on income distribution in 15 developed countries. The International Social Science Program (ISSP) fields the same topical survey once a year through continuing household-based surveys such as the General Social Survey in the USA, the General Household Survey in the UK, and the German Social Survey (ALLBUS). There are now 18 national partners in the ISSP. Similarly, the US Panel Study on Income Dynamics is coordinated with similar income surveys in European countries. Each of these involves large-scale data collection, they are governed by scientific committees, and the data that are collected are made widely available for research. However, although they provide models for new multinational observational programmes, they are all focused primarily on industrialized 
countries and thus can serve only as partial models.

\section{Observation and monitoring}

The type of large-scale observation and monitoring projects on the human dimensions of global environmental change that will be required are beginning to be identified. One nascent core project of the international HDP would involve a global-scale effort designed to provide data on individuals' perception and assessment of global environmental change. Drawing on the report of the HDP Working Group on Survey Research Data, the results of a meeting of an ad hoc advisory group, and discussion in the Standing Committee, the Advisory Committee of HDP recommended that planning begin for an international survey that currently has the working title 'Global Omnibus Environmental Survey' (GOES).

GOES would measure environmental knowledge, attitudes, and behaviours periodically in countries across the world. It would also seek data relevant to understanding how such knowledge and attitudes are formed and transformed and how they affect self-reported behaviour. The rationale for the survey is based on the fact that anthropogenic activities which contribute to global change result from accumulated individual and collective activities or behaviour. Because such behaviour is based on what human beings perceive, know, think, and feel, understanding these perceptions and reactions is crucial to getting at the anthropogenic causes of global change. It is also essential for developing the understanding that will be needed for effective mitigation and response strategies.

GOES would be conducted on a national basis, but would consist of the same survey items repeated in each country. In its first iteration, it would provide base-line data that could be used to measure changes over time. Ideally, it would be repeated every five years. Nlthough there have been several surveys that provide a glimpse of what people throughout the world know and think about the environment, these surveys have not been conducted on an internationally comparable basis, nor will they be repeated. Understanding and dealing with global change will require continual monitoring: establishing baseline data and then periodically conducting additional surveys will provide information on both current attitudes and changes in attitudes over time.

GOES would also provide data that could illuminate key theoretical issues about what people think and do concerning the environment. One important issue is the relationship between expressed preferences with respect to the environment and individuals' reports of their behaviour. It is commonplace to observe that there is a gap between expressed preferences and behaviour. GOES could contribute to confirming or denying this gap, measuring the extent to which it does exist, and accounting for differences in the size of the gap among different countries and groups within countries.

Knowledge about the formation of attitudes is crucial to understanding how they might change. Cognitive science is giving increasing emphasis to the way that cultural context shapes attitudes. GOES data could be used to test the extent to which cultural context shapes attitudes toward the global environment and would provide data for understanding how this works. Because attitudes are profoundly affected by direct experience and by media presentations, GOES data could also be used to assess the impact of direct experiences and media presentations on knowledge and attitudes.

Finally, evidence strongly suggests that attitudes towards the environment are linked to the satisfaction of basic needs. The more basic needs are satisfied, the more importance individuals seem to attach to environmental protection, preservation, and enhancement. Satisfaction of basic needs is related to levels of per capita national product, but it is not correlated perfectly, because the internal distribution of income and expectations will have a significant effect on the degree to which basic needs are satisfied across the country's population. Some societies with lower levels of per 
capita national product do a better job of satisfying basic needs than those with higher per capita GNPs.

GOES would consist of a standard set of questions that would be the core of the questionnaire and used in all participating countries. In addition, governments could add modules on topics of particular policy interest. The survey would thus provide data for internal use as well as for comparative multinational research. To ensure that the survey was fully comparable, GOES would provide training opportunities for social scientists in each country. This would also provide a form of technology transfer to developing countries and would add to the numbers of trained social scientists worldwide capable of conducting research on human aspects of global environmental change.

GOES would be conducted in as many countries as possible, but at a minimum would have to include the countries that make greatest contributions to global environmental change. This would include, among developed countries, the USA, the European Community, and Japan; and, among developing countries, Bangladesh, Brazil, China, India, Indonesia, Korea, Mexico, Nigeria, and Pakis$\tan$. It would also include Russia, and some sample of the countries in eastern Europe that formerly had centrally planned economies. With this group of countries, the survey would encompass more than two-thirds of the world's population, more than $84 \%$ of the world product (the sum of all countries' gross domestic products), and more than $70 \%$ of greenhouse gas emissions. ${ }^{20}$

National samples for GOES must be drawn so that the results of the surveys could be used in combination with data drawn from natural science studies. This will require considerable statistical ingenuity and virtuosity. The problem can be illustrated by considering the estimated effects of climate change for selected regions presented by the Intergovernmental Panel on Climate Change (IPCC). ${ }^{21}$ The IPCC projected the effects of climate change within areas defined by degrees of latitude and longitude. However, these areas bear little rela- tionship to those which social scientists normally use that are defined by administrative and political boundaries. To link social science data with physical phenomena will probably require social scientists to draw larger than usual samples. In any case, the sampling frame will have to be developed in collaboration with natural scientists.

Although the WFS provides a model for GOES, it also highlights problems to be avoided. In the WFS, governments were at times able to exert too much control over the data. In some cases, governments did not permit the questionnaire to contain what they felt were 'sensitive questions'. In others, they would not release WFS data for scientific use after the survey, or would do so only after a lengthy waiting period which disrupted researchers' schedules. In part, this latter problem stems from the fact that there was no effective long-term provision for making WFS data available for research purposes. In planning the successor Demographic and Health Survey, measures were designed to correct these problems. Their effects must be monitored to see if in lact they have corrected the problems.

Because GOES would be repeated at five-year intervals, it would become increasingly valuable over time as it began to measure trends and changes in attitudes, knowledge, and behaviour. For this reason, there must be prior agreement on data availability, and the data must be archived and made accessible through a stable institution and in a form that permits them to be used by researchers from all countries.

GOFS would also be able to build on the experience of various multinational environmental surveys currently in the planning stages. These surveys would be used in constructing the GOES questionnaire, developing pilot studies, and identifying technical problems in conducting a multinational environmental survey.

It will be necessary to obtain funding for the survey from several sources. Within the industrialized countries, the GOES would be financed by the usual science-funding mechanisms. International funding 
would be essential to cover the costs connected with international coordination and the costs of administering the survey in other countries.

Other topics that require globalscale observation and monitoring activities could be added to GOES as research on the human interactions in global environmental change proceeded. Possible topics are individual attitudes relating to actual and expected levels of consumption; energy use; and transportation. To understand these topics, it will be important to obtain data about capital stocks and the rates of their replacement.

\section{Process studies}

A second type of large-scale, multinational research project involves the accumulation of case studies of similar phenomena in a large number of countries for comparative analysis. In the terminology of global change research, these would be process studies.

There are several examples of such process studies. One is the Critical Zones Project currently being conducted by Professor Roger Kasperson and a multinational team. In this study, twelve areas of rapid environmental deterioration are being examined to compare public perception of environmental change and public policy intervention. A second is the ambitious project on societal learning conducted by a multinational team led by Professor William C. Clark. This project examines how several countries in North America and Europe have responded to various elements of global change. The European Science Foundation has completed a project on the management of environmental change in the North Sea and the Mediterranean.

Another example is the research on land use/land cover that is currently being planned by a joint HDP-IGBP working group chaired by Professor Billie L. Turner. The questions that this project will address are: acute conflict, Thomas F. Homer-Dixon lists altered water supplies as one of the primary effects likely to stimulate conflict. See Thomas F. Homer-Dixon, 'On the threshold: Environmental changes as causes of acute conflicts', International Security, Vol 16, No 2, Fall 1991, pp 76116. and the middle of the next century?

- What are the major human causes of land-use change and their variation by spatial (and temporal) context?

The ultimate aim of the project is to develop a Global Land Use/Land Cover Projection Model. This cannot be done by using global aggregates because the dynamics of change in land use/land cover differ by region. Instead, the global model will have to be built by bringing together regional models. Regional case studies will be the first step in creating these regional models. These case studies will have to be conducted according to a common framework so that they can be brought together at a later stage.

A multinational comparative water survey provides another, though at this stage hypothetical, example. The availability of sufficient water resources for food, agriculture, and industrial production promises to be one of the major global environmental problems of the coming century. ${ }^{22}$ Yet there is still only limited knowledge of water resources and water needs on a country-by-country basis, and little projection of future water needs and supplies.

A water survey that would provide extensive information on water in many countries - the stock of water, its quality, and the current and anticipated demand - is essential for both anticipating environmental problems and conducting research on anthropogenic and biogeochemical aspects of the hydrological cycle. Although there is good information about the various processes of change in the hydrological cycle, there are little basic data on stocks and flows of current and future water supplies on a country basis where decisions are made about price, regulatory requirements and access. For example, we know that deforestation has serious hydrological implications. Not only do changes in forest cover affect the amount of water available, but the introduction of irrigation and the increase in population on the same land place immense demands on the area's water supplies. The questions are how will this affect regional climate and water supplies and what 
are its implications under conditions of certain population increase?

Among the information that would be obtained in the water survey would be basic data on water stocks and flows. That is, what are the stocks of water available both within the country and from other countries, what is the quality of this water, and what are current and anticipated water needs and supplies? One idea to explore is whether it is possible to develop a system of national water accounts, hased on the social accounts developed by Sir Richard Stone. ${ }^{23}$ The project would also provide information on water's impact on food supplies, such as the availability of water for irrigation, for providing fish and aquaculture, and in household and commercial food preparation.

In addition, it would provide data on the impact of water supplies on the hydrologic cycle and regional climate change. External influences on water supplies, both anthropogenic and climate-induced (such as transborder water sharing; increases in groundwater pollution through in-country or foreign agricultural or industrial cffluents; increases in salinity; and changes in river volumes) would be reported. Legal and regulatory limitations on water pollution, access to water, and the cost of water would be reported. Ultimately the study would provide estimates for each country of the adequacy of water supplies under various population growth and distribution scenarios; the adequacy of water supplies under various agricultural and land use change scenarios; and the adequacy of water supplies under various industrial and technological growth scenarios.

The information obtained in the survey would be useful for both research and policy purposes. It is needed for further multinational research in both the social and the natural sciences and is essential for policy purposes within individual countries. Because of the potential political implications of the water survey, the rescarch tcams should bc made up half of local members and half of international social scientists. It will be important for social scientists from industrial countries to be involved in the developing countries' water surveys, and for developing countries' social scientists to participate in the water surveys of industrial countries.

\section{A strategic orientation}

As social science moves to address global issues such as global environmental change, the necessity of adopting big science concepts, techniques, and goals is clear. By definition, the outstanding research problems require a multinational and multidisciplinary focus and orientation, and multinational and multidisciplinary participation. This presents the social sciences with research problems on a scale previously unknown. For the social sciences, then, this is big science. It is also clear, however, that as social science embarks on big science, it must do so with a clear strategic vision.

Big social science projects will be expensive in terms of both expenditures and the allocation of scarce scientific talent. Only a few big social science projects will be possible. After six years, IGBP, with a thorough and exacting vetting process, has only five core projects. The social sciences should expect to move with the same caution and emphasis on scientific quality and scientific significance. Big science projects will be more visible to governmental authorities and to broad publics than is often the case in social science research, and programme participants and managers will quite rightly be faced with strict standards of accountability.

Coordination of big social science projects requires institutional structures that can dependably maintain the same standards from country to country and ensure that all participating countries receive adequate financial and technical assistance. After a survey such as GOES has been conducted, further institutional support will be necessary to ensure that the data will be available to both researchers and governments.

Clearly, big social science projects must be chosen carefully. The first criterion in choosing projects, of course, must be scientific. Big social science projects should be undertaken only when they are necessary to 
address significant scientific questions. A second criterion stems from the level of expenditures that will be required and the opportunity costs that will be involved. The questions to be addressed must have importance for national and international public policy. This is the most important of the external criteria emphasized by Weinberg. Public and private funding agencies face too many competing needs to be able to allocate large amounts of funds to projects that are not related to important public needs.

A final criterion is that big social science projects should have a reasonable prospect of yielding useful knowledge. Failure to do this will be very costly to the place and future of social science in modern society. The im- portance of undertaking projects with a strong prospect of yielding useful knowledge means that they should not be undertaken unless the social science community is ready. In addition to the requisite institutional and financial resources, readiness involves having concepts and theory relevant to the issue, adequate cadres of skilled researchers, a sense of the data that are available and required, and a careful design for accomplishing the work.

Big social projects are the only way to provide the research resources necessary for global-scale studies of environmental change. The social science community is ready to launch such projects. It should now proceed in full awareness of the challenges of the task. 